\title{
Clinical Utility of Additional Measurement of Total Lung Capacity in Diagnosing Obstructive Lung Disease in Subjects With Restrictive Pattern of Spirometry
}

\author{
Hyun Lee MD, Boksoon Chang MD, Kyunga Kim PhD, Won Jun Song MD, Hae Ri Chon MD, \\ Hyung Koo Kang MD, Jung Soo Kim MD, Byeong-Ho Jeong MD PhD, Yeon-Mok Oh MD PhD, \\ Won-Jung Koh MD PhD, and Hye Yun Park MD PhD
}

\begin{abstract}
BACKGROUND: Total lung capacity (TLC), forced expiratory flow between 25 and $75 \%\left(\mathbf{F E F}_{25-75 \%}\right)$, peak expiratory flow (PEF), or post-bronchodilator volume response is recommended to detect obstructive abnormalities in the lung. The present study was performed to evaluate the usefulness of these pulmonary function test (PFT) parameters to diagnose obstructive lung disease in subjects with a restrictive pattern of spirometry. METHODS: A retrospective study was conducted in 64 subjects with a restrictive pattern of spirometry (normal $\mathrm{FEV}_{1} / \mathrm{FVC}$ and low FVC) out of 3,030 patients who underwent all pre- and post-bronchodilator spirometry and lung volume measurement between April 2008 and December 2010. After subjects were clinically classified into those with obstructive lung disease, restrictive lung disease, and mixed lung disease, the agreements between the clinical diagnosis and PFT classification according to TLC, FEF $_{25-75 \%}$, PEF, and post-bronchodilator response criteria were compared. RESULTS: Of 64 subjects, $18(28.1 \%)$ were classified with obstructive lung disease, $39(60.9 \%)$ had restrictive lung disease, $1(1.6 \%)$ had mixed lung disease, and $6(9.4 \%)$ had no clinical lung disease. Among the 58 subjects with clinical lung disease, $22(37.9 \%), 37(63.8 \%), 33(56.9 \%)$, and $3(5.2 \%)$ were classified as having obstructive pattern based on TLC, FEF $_{25-75 \%}$, PEF, and post-bronchodilator response criteria, respectively. The kappa coefficients for the agreement between the clinical classification and PFT classification using TLC, $\mathrm{FEF}_{25-75 \%}, \mathrm{PEF}$, and post-bronchodilator response criteria in 58 subjects were $0.59,0.18,0.17$, and < 0.01, respectively. CONCLUSIONS: The additional measurement of TLC is more useful than $\mathrm{FEF}_{25-75 \%}$, PEF, and post-bronchodilator response for diagnosis of obstructive lung disease in subjects with a restrictive pattern of spirometry, when obstructive lung disease is clinically suspected. Key words: airway obstruction; maximal midexpiratory flow; spirometry; peak expiratory flow; total lung capacity; obstructive lung diseases. [Respir Care 2016;61(4):475-482. (C) 2016 Daedalus Enterprises]
\end{abstract}

\section{Introduction}

Pulmonary function tests (PFTs) are fundamental noninvasive tests to assess obstructive and restrictive defects

Drs Lee, Song, Chon, Kang, JS Kim, Jeong, Koh, and Park are affiliated with the Division of Pulmonary and Critical Care Medicine, Department of Medicine, Samsung Medical Center, Sungkyunkwan University School of Medicine, Seoul, Korea. Dr Chang is affiliated with the Department of Pulmonary and Critical Care Medicine, Kyung Hee University Hospital at Gangdong, School of Medicine, Kyung Hee University, Seoul, Korea. Dr K Kim is affiliated with the Biostatistics and Clinical Epidemiology Center, Samsung Medical Center, Seoul, Korea. Dr Oh is affiliated with the Division of Pulmonary and Critical Care Medicine, Department of Internal Medicine, Asan Medical Center, University of Ulsan College of Medicine, Seoul, Korea. in patients with lung disease. However, some patients have obstructive lung disease and exhibit a restrictive spirometry pattern defined by normal forced expiratory volume in 1 second $\left(\mathrm{FEV}_{1}\right) /$ forced vital capacity $(\mathrm{FVC})$ and low $\mathrm{FVC}$,

\footnotetext{
The authors have disclosed no conflicts of interest.

The first 2 authors contributed equally to this work.

Correspondence: Hye Yun Park MD PhD, Division of Pulmonary and Critical Care Medicine, Department of Medicine, Samsung Medical Center, Sungkyunkwan University School of Medicine, 81 Irwon-ro, Gangnam-gu, Seoul 135-710, Korea. E-mail: hyeyunpark@skku.edu.
}

DOI: $10.4187 /$ respcare.04222 
which can cause false positive or false negative interpretations leading to inappropriate treatment selection in the absence of additional clinical information. The current interpretative strategy for PFT, as proposed by the American Thoracic Society/European Respiratory Society Task Force, recommends measurement of additional lung volume parameters to distinguish obstructive patterns from restrictive patterns in patients with normal $\mathrm{FEV}_{1} / \mathrm{VC}$ and low VC. ${ }^{1}$ In particular, total lung capacity (TLC) is considered as an important element to distinguish obstruction from restriction. In interpretative algorithms, the presence of a restrictive defect is suggested when both VC and TLC are below the lower limit of normal range. ${ }^{1}$ On the other hand, when $\mathrm{VC}$ is lower than the lower limit of normal and TLC is higher than the lower limit of normal, the presence of a restrictive defect can be excluded. ${ }^{1}$

The American Thoracic Society/European Respiratory Society Task Force suggests that additional PFT parameters, such as forced expiratory flow and post-bronchodilator improvement in $\mathrm{FEV}_{1}$ or FVC, may also be helpful in diagnosing obstructive lung disease in patients with a restrictive pattern. Likewise, several studies have shown that forced expiratory flow between 25 and $75 \%\left(\mathrm{FEF}_{25-75 \%}\right)$ is less effort-dependent and more reflective of small airway patency than $\mathrm{FEV}_{1}{ }^{2-5}$ and that peak expiratory flow (PEF) may be a screening method for air flow obstruction. ${ }^{6,7}$ In addition, it has been well noticed that significant improvement in $\mathrm{FEV}_{1}$ or FVC after bronchodilator use is characteristic of reversible air flow limitation. ${ }^{1}$ Although a previous study investigated the clinical usefulness of TLC to identify obstructive lung disease, such as COPD and asthma, in subjects with restrictive pattern of spirometry, ${ }^{8}$ a comparison of the utility of TLC, $\mathrm{FEF}_{25-75 \%}$, PEF, and the post-bronchodilator response of $\mathrm{FEV}_{1}$ or FVC to identify obstructive lung disease in subjects with restrictive spirometry patterns has not yet been studied. Thus, the purpose of this study was to compare the agreement between clinical diagnoses and PFT interpretation using TLC, $\mathrm{FEF}_{25-75 \%}$, $\mathrm{PEF}$, and post-bronchodilator response in subjects with restrictive spirometry patterns.

\section{Methods}

\section{Subjects}

A total of 3,030 patients underwent PFT with preand post-bronchodilator spirometry and lung volume measurement at the Samsung Medical Center (a 1,961bed referral hospital in Seoul, Korea) between April 2008 and December 2010. After excluding 2,966 patients including those with $\mathrm{FEV}_{1} / \mathrm{FVC}<0.70(n=$ $2,814)$ and those with $\mathrm{FEV}_{1} / \mathrm{FVC} \geq 0.70$ and $\mathrm{FVC} \geq$ $80 \%$ predicted $(n=152)$, total 64 patients with $\mathrm{FEV}_{1} / \mathrm{FVC} \geq 0.70$ and $\mathrm{FEV}<80 \%$ predicted were

\section{QUICK LOOK}

\section{Current knowledge}

Pulmonary function tests are fundamental noninvasive tests to assess obstructive and restrictive defects in subjects with lung disease. However, some subjects have obstructive lung disease and exhibit a restrictive spirometry pattern. Several lung function parameters, such as total lung capacity, forced expiratory flow between 25 and $75 \%$, peak expiratory flow, or post-bronchodilator volume response, are recommended to detect obstructive abnormalities in the lung, but comparison of lung function parameters to identify obstructive lung disease in subjects with restrictive spirometry patterns has not yet been studied.

\section{What this paper contributes to our knowledge}

Total lung capacity gives a strong relationship with clinical diagnosis of obstructive lung disease in subjects with restrictive spirometry patterns. The additional measurement of TLC is more useful than other lung function parameters, including forced expiratory flow between 25 and $75 \%$, peak expiratory flow, and postbronchodilator volume response, in diagnosing obstructive lung disease in subjects with a restrictive pattern of spirometry, when clinicians suspect obstructive lung disease.

included (Fig. 1). When subjects underwent more than one PFT during the study period, data from only the first measurement were used in our analysis. This study was approved by the institutional review board of Samsung Medical Center; we were allowed to review and publish information obtained from patient records. The requirement for informed consent was waived.

\section{Measurement of Lung Function}

Spirometry was performed as recommended by the American Thoracic Society ${ }^{9}$ using a Vmax 22 system (CareFusion, San Diego, California). Absolute values of FVC and $\mathrm{FEV}_{1}$ were obtained, and the percent predicted values for $\mathrm{FEV}_{1}$ and $\mathrm{FVC}$ were calculated using the reference equation obtained upon analysis of a representative Korean sample. ${ }^{10}$ TLC was measured using body plethysmography (V62J Body Box, CareFusion, San Diego, California), with predicted values calculated using the reference equations of the European Community for Coal and Steel, ${ }^{11}$ which have been shown to be the most suitable for determining lung volumes in Korean subjects. ${ }^{12}$ 


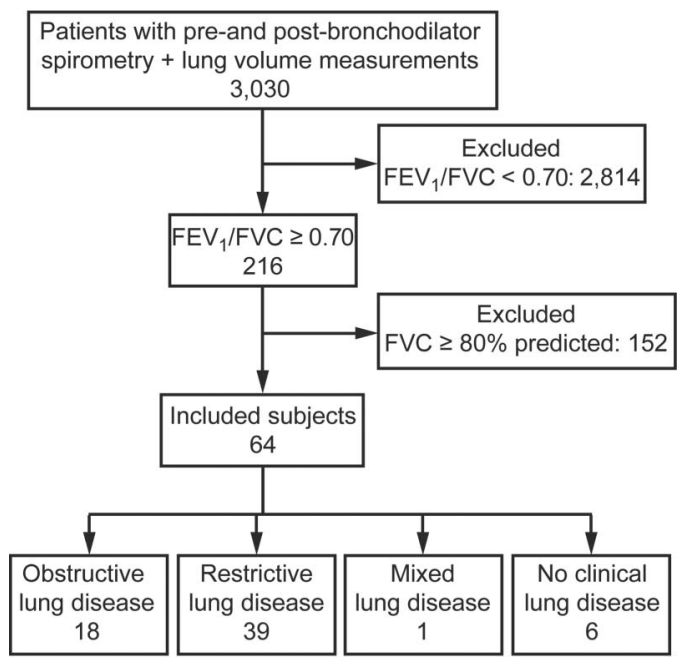

Fig. 1. Flow chart.

\section{Classification of Clinical Diagnosis}

Subjects were classified with obstructive, restrictive, mixed, and no clinical lung diseases by consensus between 2 pulmonary physicians who reviewed all medical records, chest $\mathrm{x}$-rays, chest computed tomography scans, bronchoscopic findings, and treatments. Asthma, COPD, bronchiectasis, and bronchiolitis were classified as obstructive lung disease. ${ }^{13}$ Bronchial obstruction without atelectasis caused by endobronchial narrowing due to tuberculosis, endobronchial tumors, or extrinsic mass, were also classified as obstructive lung disease. Subjects who had idiopathic and connective tissue-associated interstitial lung disease, scoliosis, or neuromuscular diseases were classified as having restrictive lung disease. In addition, subjects who developed bronchiolitis obliterans organizing pneumonia after undergoing stem cell transplantation were classified as having restrictive lung disease. ${ }^{14}$ Lung cancers consisting of large tumors or having large amounts of pleural effusion or atelectasis were also diagnosed as restrictive lung disease. Post-lobectomy or pneumonectomy status, pleural disease, large volumes of ascites, diaphragmatic elevation, mitral valve disease, ${ }^{15}$ heart failure, ${ }^{16}$ benign atelectasis or lung volume loss, pneumonic consolidation, and multiple lung nodules were also included in the restrictive lung disease category. Subjects were designated as having mixed lung disease when criteria for both obstructive and restrictive disease were met. Subjects who were not defined by the criteria described above were classified as having no pulmonary disease.

\section{PFT Interpretation}

The presence of air flow limitation was assessed based on a fixed ratio; the criterion was defined as $\mathrm{FEV}_{1} / \mathrm{FVC}<$
0.70. Of subjects with normal $\mathrm{FEV}_{1} / \mathrm{FVC}(\geq 0.70)$ and low FVC ( $<80 \%$ predicted), ${ }^{17}$ those with TLC $\geq 80 \%$ predicted, ${ }^{18}$ those with $\mathrm{FEF}_{25-75 \%}<70 \%$ predicted, ${ }^{19}$ those with $\mathrm{PEF}<80 \%$ predicted, 6,7 and those with a change in $\mathrm{FEV}_{1}$ or $\mathrm{FVC}$ of at least $12 \%$ and $200 \mathrm{~mL}^{1}$ were interpreted as having obstructive pattern by TLC, $\mathrm{FEF}_{25-75 \%}$, $\mathrm{PEF}$, and post-bronchodilator response criteria, respectively.

\section{Statistical Analysis}

Data were presented as the number (percentage) of subjects for categorical variables and median with interquartile ranges for continuous variables. For the 4 PFT criteria, TLC, $\mathrm{FEF}_{25-75 \%}, \mathrm{PEF}$, and post-bronchodilator response, kappa statistics were used to assess the concordance between obstructive lung disease diagnoses, for which mixed type disease was included as obstructive disease, and PFT classifications. In this analysis scheme, a kappa of $>0.75$ represented excellent agreement, $0.40-0.75$ represented a fair to good agreement, and $<0.40$ was indicative of poor agreement. ${ }^{20}$ The performance of PFT classification in predicting clinically obstructive disease was also evaluated by sensitivity, specificity, positive predictive value, and negative predictive value. Concordance and prediction performance were compared between the PFT classification criteria using a bootstrapping-based nonparametric method that generated a null distribution of test statistics by resampling from the original data set with replacement data over a total of 1,000 iterations. ${ }^{21}$ All tests were 2-sided, and $P$ values of $<.05$ were considered statistically significant. All analyses were performed using SAS version 9.4 (SAS Institute, Cary, North Carolina) and R 3.1.0 (R Foundation for Statistical Computing, Vienna, Austria).

\section{Results}

\section{Clinical and PFT Classification}

As shown in Table 1, the median age of the 64 subjects included in our final analysis was 57.0 y (interquartile range 45.0-65.0 y) and consisted of 35 men (54.7\%) and 29 women $(45.3 \%)$. All subjects were Korean. The baseline PFT results were as follows: median $\mathrm{FEV}_{1} / \mathrm{FVC}$ was 0.79 (interquartile range $0.74-0.84$ ), median $\mathrm{FVC}$ was $2.3 \mathrm{~L}$ (67.0\% predicted), median $\mathrm{FEV}_{1}$ was $1.8 \mathrm{~L}(70.0 \%$ predicted), median TLC was $3.8 \mathrm{~L}$ (77.0\% predicted), median $\mathrm{FEF}_{25-75 \%}$ was $1.8 \mathrm{~L} / \mathrm{s}$ (61.5\% predicted), and median $\mathrm{PEF}$ was $5.1 \mathrm{~L} / \mathrm{s}$ (76.5\% predicted), respectively. Of these subjects, 18 were classified as having obstructive lung disease, 39 as having restrictive lung disease, 1 as having mixed lung disease, and 6 as having no clinical lung disease (Table 2). 
Table 1. Baseline Characteristics of 64 Subjects With Restrictive Pattern

\begin{tabular}{|c|c|}
\hline Characteristics & Values \\
\hline Age, median (IQR) y & $57.0(45.0-65.0)$ \\
\hline Male sex, $n(\%)$ & $35(54.7)$ \\
\hline Korean ethnicity, $n(\%)$ & $64(100)$ \\
\hline \multicolumn{2}{|l|}{ Baseline pulmonary function test } \\
\hline $\mathrm{FEV}_{1} / \mathrm{FVC}$, median (IQR) & $0.79(0.74-0.84)$ \\
\hline FVC, median (IQR) L & $2.3(1.9-2.7)$ \\
\hline FVC, median (IQR) \% predicted & $67.0(60.3-74.0)$ \\
\hline $\mathrm{FEV}_{1}$, median (IQR) L & $1.8(1.5-2.3)$ \\
\hline $\mathrm{FEV}_{1}$, median (IQR) \% predicted & $70.0(65.3-79.8)$ \\
\hline TLC, median (IQR) L & $3.8(3.3-4.5)$ \\
\hline TLC, median (IQR) \% predicted & $77.0(69.3-86.8)$ \\
\hline $\mathrm{FEF}_{25-75 \%}$, median (IQR) L/s & $1.8(1.2-2.4)$ \\
\hline $\mathrm{FEF}_{25-75 \%}$, median (IQR) \% predicted & $61.5(43.0-77.8)$ \\
\hline PEF, median (IQR) L/s & $5.1(4.2-6.2)$ \\
\hline PEF, median (IQR) \% predicted & $76.5(64.3-90.8)$ \\
\hline \multicolumn{2}{|c|}{$\begin{array}{l}\mathrm{IQR}=\text { interquartile range } \\
\mathrm{TLC}=\text { total lung capacity } \\
\mathrm{FEF}_{25-75 \%}=\text { forced expiratory flow between } 25 \text { and } 75 \% \text { of vital capacity } \\
\mathrm{PEF}=\text { peak expiratory flow }\end{array}$} \\
\hline
\end{tabular}

Of the 58 subjects with clinical lung disease, 22 (37.9\%), 37 (63.8\%), $33(56.9 \%)$, and $3(5.2 \%)$ were classified as having obstructive pattern as determined by TLC, $\mathrm{FEF}_{25-75 \%}, \mathrm{PEF}$, and post-bronchodilator response criteria, respectively (Table 3). Fifteen subjects met the criteria of obstructive pattern according to both TLC and $\mathrm{FEF}_{25-75 \%}$ parameters, and 23 subjects met the criteria for both $\mathrm{FEF}_{25-75 \%}$ and PEF parameters. Eleven subjects met the criteria of obstructive pattern according to 3 parameters, including TLC, $\mathrm{FEF}_{25-75 \%}$, and PEF parameters, whereas none met the criteria according to all 4 parameters.

\section{Concordance Between Clinical and PFT Classifications}

As noted in Figure 2, the PFT classification using TLC showed good agreement $\left(\kappa_{\mathrm{TLC}}=0.59\right)$ with the clinical diagnosis of obstructive lung disease, whereas the PFT classifications obtained from the $\mathrm{FEF}_{25-75 \%}, \mathrm{PEF}$, and post-bronchodilator response were in poor agreement $\left(\kappa_{\mathrm{FEF}}=0.18, \kappa_{\mathrm{PEF}}=0.17\right.$, and $\kappa_{\mathrm{post}-\mathrm{BD}}<0.01$, respectively). As shown in Table 4, the difference in kappa values was significant between TLC and the other criteria (95\% CI $0.10-0.71, P=.01$ for $\kappa_{\mathrm{TLC}}$ vs $\kappa_{\mathrm{FEF}} ; 95 \%$ CI $0.12-0.71, P=.01$ for $\kappa_{\mathrm{TLC}}$ vs $\kappa_{\mathrm{PEF}} ; 95 \%$ CI $0.32-0.85$, $P<.001$ for $\kappa_{\mathrm{TLC}}$ vs $\left.\kappa_{\text {post-BD }}\right)$. However, the difference among the other 3 criteria was not significant $(P=.96$ for $\kappa_{\mathrm{FEF}} \mathrm{VS} \kappa_{\mathrm{PEF}}, P=.17$ for $\kappa_{\mathrm{FEF}} \mathrm{vs} \kappa_{\mathrm{post}-\mathrm{BD}}, P=.25$ for $\kappa_{\text {post-BD }}$ VS $\left.\kappa_{\mathrm{PEF}}\right)$.
Table 2. Clinical Diagnosis of 64 Subjects With Restrictive Pattern

\begin{tabular}{lc}
\hline \hline \multicolumn{1}{c}{ Clinical Diagnosis } & $n(\%)$ \\
\hline Obstructive lung disease & $18(28.1)$ \\
Lung cancer with endobronchial narrowing & $6(9.2)$ \\
Emphysema & $3(4.7)$ \\
Bronchiectasis & $2(3.1)$ \\
Bronchial asthma & $2(3.1)$ \\
Churg-Strauss syndrome & $2(3.1)$ \\
Pulmonary tuberculosis with endobronchial & $2(3.1)$ \\
narrowing & \\
Bronchomalacia & $1(1.6)$ \\
Restrictive lung disease & $39(60.9)$ \\
Idiopathic pulmonary fibrosis & $6(9.4)$ \\
Lung resection & $6(9.4)$ \\
Other interstitial lung disease except & $6(9.4)$ \\
idiopathic pulmonary fibrosis & \\
Severe mitral valve disease & $6(9.4)$ \\
Pleural thickening due to history of & $3(4.7)$ \\
tuberculosis pleurisy & \\
Bronchiolitis obliterans associated & $2(3.1)$ \\
peripheral blood stem cell transplantation & $2(3.1)$ \\
Lung volume loss & $2(3.1)$ \\
Multiple lung metastasis & $1(1.6)$ \\
Amyotrophic lateral sclerosis. & $1(1.6)$ \\
Chronic empyema & $1(1.6)$ \\
Diaphragmatic eventration & $1(1.6)$ \\
Large amount of ascites & $1(1.6)$ \\
Severe kyphosis & $1(1.6)$ \\
Congenital heart disease with cardiomegaly & $1(1.6)$ \\
Obstructive and restrictive lung disease & $1(1.6)$ \\
Bronchiectasis with fibrothorax & $6(9.4)$ \\
No pulmonary disease by clinical diagnosis & $2(3.1)$ \\
Acute cholecystitis & $2(3.1)$ \\
Mechanical ileus & $1(1.6)$ \\
Small bowel intussusception & \\
Ureteral injury & \\
\hline
\end{tabular}

\section{Prediction Performance of PFT Classifications}

The sensitivity of the post-bronchodilator response criterion $(5.3 \%)$ was significantly lower than TLC, $\mathrm{FEF}_{25-75 \% \text {, }}$ and PEF criteria (79.0\% for both TLC and $\mathrm{FEF}_{25-75 \%}$ and $68.4 \%$ for PEF) (Table 5). The specificity of the postbronchodilator response (94.9\%) was slightly higher than the TLC $(82.1 \%)$ criteria, although this difference was not statistically significant $(P=.10)$. The $\mathrm{FEF}_{25-75 \%}$ and $\mathrm{PEF}$ criteria exhibited significantly lower specificity (43.6 and $51.3 \%$ ) compared with the other 2 criteria (all $P<.001$ ). Finally, the TLC criterion had a significantly higher positive predictive value $(68.2 \%)$ than $\mathrm{FEF}_{25-75 \%}$ and PEF (40.5\%, $P=.005$ and $40.6 \%, P=.005)$ as well as a significantly higher negative predictive value (88.9\%) compared with the post-bronchodilator response criterion (67.3\%, $P<.001)$. 


\section{Lung Volume in a Restrictive Spirometry Pattern}

Table 3. Interpretation of Pulmonary Function Test Parameters of 58 Subjects With Clinical Lung Disease, Compared With Clinical Classification

\begin{tabular}{|c|c|c|c|c|}
\hline \multirow{2}{*}{ Clinical Classification } & \multicolumn{4}{|c|}{ Obstructive Pattern Based on PFT Parameters, $n(\%)$} \\
\hline & TLC $\geq 80 \%$ Predicted & $\mathrm{FEF}_{25-75 \%}<70 \%$ Predicted & PEF $<80 \%$ Predicted & Post-Bronchodilator Response \\
\hline Obstructive disease $(n=18)$ & $14(77.8)$ & $15(83.3)$ & $9(50.0)$ & $1(5.6)$ \\
\hline Restrictive disease $(n=39)$ & $7(17.9)$ & $22(56.4)$ & $23(59.0)$ & $2(5.1)$ \\
\hline Mixed disease $(n=1)$ & $1(100)$ & $0(0)$ & $1(100)$ & $0(0)$ \\
\hline Total $(n=58)$ & 22 & 37 & 33 & 3 \\
\hline \multicolumn{5}{|c|}{$\begin{array}{l}\mathrm{PFT}=\text { pulmonary function test } \\
\mathrm{TLC}=\text { total lung capacity } \\
\mathrm{FEF}_{25-75}=\text { forced expiratory flow between } 25 \text { and } 75 \% \text { of vital capacity } \\
\mathrm{PEF}=\text { peak expiratory flow }\end{array}$} \\
\hline
\end{tabular}

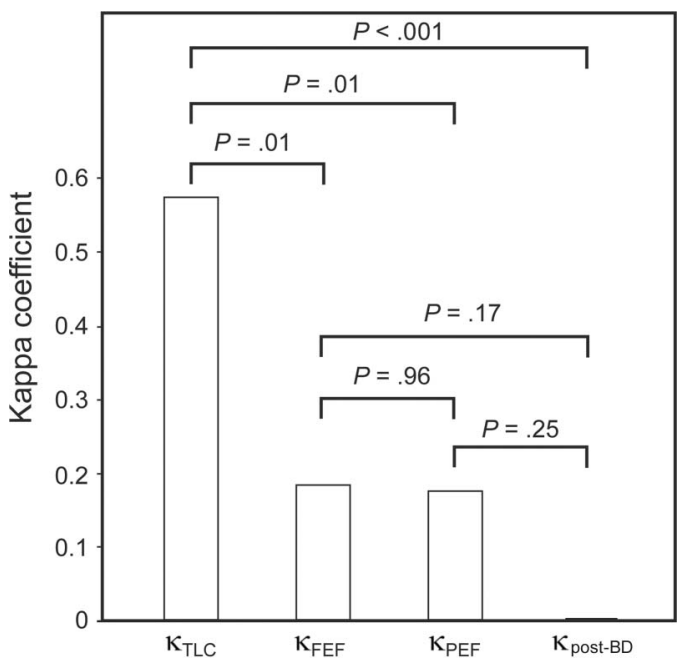

Fig. 2. The kappa coefficients for agreement in the diagnosis of obstruction between the clinical classification and the PFT classification using TLC, $\mathrm{FEF}_{25-75 \%}$, PEF, and post-bronchodilator response in 58 subjects with clinical lung disease. $\kappa_{\mathrm{TLC}}=$ the kappa coefficient for agreement in the diagnosis of obstructive disease between clinical diagnosis and total lung capacity (TLC) criteria; $\kappa_{\mathrm{FEF}}=$ the kappa coefficient for agreement in the diagnosis of obstructive disease between clinical diagnosis and forced expiratory flow between 25 and $75 \%$ of vital capacity $\left(\mathrm{FEF}_{25-75 \%}\right)$ criteria; $\kappa_{\mathrm{PEF}}=$ the kappa coefficient for agreement in the diagnosis of obstructive disease between clinical diagnosis and peak expiratory flow (PEF) criteria; $\kappa_{\text {post-BD }}=$ the kappa coefficient for agreement in the diagnosis of obstructive disease between clinical diagnosis and post-bronchodilator response criteria.

\section{Discussion}

In the present study, $29.7 \%$ of subjects with restrictive spirometry patterns were found to have clinically classified obstructive lung disease. The agreement of clinical diagnosis of obstructive lung disease with PFT interpretation using TLC was significantly higher than the agreements obtained with PFT interpretation using $\mathrm{FEF}_{25-75 \%}$ or the post-bronchodilator response in subjects with restrictive patterns defined as normal $\mathrm{FEV}_{1} / \mathrm{FVC}$ and low $\mathrm{FVC}$.
In addition, the sensitivity and specificity of PFT interpretation using TLC for the diagnosis of clinical obstructive lung disease were 0.79 and 0.82 , respectively, whereas the sensitivity and specificity of $\mathrm{FEF}_{25-75 \%}$ were 0.79 and 0.44 , and the sensitivity and specificity of the post-bronchodilator response were 0.05 and 0.95 . Taken together, these results suggested that obtaining additional measurements for TLC might be useful for differentiating obstructive lung disease from other diseases that produce restrictive patterns of spirometry.

In general, air flow obstruction is diagnosed based on an $\mathrm{FEV}_{1} / \mathrm{FVC}<0.70$ using spirometry alone. However, some subjects with obstructive lung disease have been reported to have restrictive patterns associated with normal $\mathrm{FEV}_{1} / \mathrm{FVC}$ and low FVC on spirometry due to concomitant decreases in $\mathrm{FEV}_{1}$ and $\mathrm{FVC}$, which can cause false positive or false negative interpretations in the absence of other clinical information. One possible cause of this phenomenon is failure of the patient to inhale completely or exhale long enough to empty the lungs to the residual volume. ${ }^{1}$ In this situation, normal TLC will be recorded. In the present study, among 19 subjects with clinically classified obstructive lung disease (including 1 mixed disease), 15 subjects (78.9\%) had concomitant decreases of $\mathrm{FEV}_{1}$ and FVC with normal TLC.

Another potential mechanism that may contribute to a restrictive spirometry pattern in patients with obstructive lung disease is patchy collapse of the small airways early in exhalation, which results in slowing in the terminal portion of the spirogram. ${ }^{1}$ To account for this possibility, the American Thoracic Society/European Respiratory Society Task Force suggested ${ }^{1}$ that TLC may be normal, and the $\mathrm{FEF}_{25-75 \%}$ may be low. Moreover, when normal $\mathrm{FEV}_{1} / \mathrm{FVC}$ with concomitant low $\mathrm{FEV}_{1}$ and FVC persists upon sustained effort, the American Thoracic Society/European Respiratory Society Task Force also suggests repeating the spirometry after treatment with an inhaled bronchodilator in order to explore the presence of reversible air flow obstruction. ${ }^{1}$ 


\section{Lung Volume in a Restrictive Spirometry Pattern}

Table 4. Comparison of Kappa Value Between Various Pulmonary Function Test Parameters for the Diagnosis of Obstruction in 58 Subjects With Clinical Lung Disease

\begin{tabular}{|c|c|c|c|c|}
\hline Kappa & $\begin{array}{l}\text { Mean Difference of Kappa } \\
\text { Values of } 1,000 \text { Samples* }\end{array}$ & SD & $95 \% \mathrm{CI}$ & $P$ \\
\hline TLC vs $\mathrm{FEF}_{25-75 \%}$ & 0.41 & 0.15 & $0.10-0.71$ & .01 \\
\hline TLC vs PEF & 0.41 & 0.15 & $0.12-0.71$ & .01 \\
\hline TLC vs post-bronchodilator response & 0.59 & 0.14 & $0.32-0.85$ & $<.001$ \\
\hline $\mathrm{FEF}_{25-75 \%}$ vs PEF & 0.01 & 0.15 & -0.28 to 0.30 & .96 \\
\hline $\mathrm{FEF}_{25-75 \%}$ vs post-bronchodilator response & 0.18 & 0.13 & -0.08 to 0.44 & .17 \\
\hline Post-bronchodilator response vs PEF & -0.17 & 0.15 & -0.47 to 0.12 & .25 \\
\hline \multicolumn{5}{|c|}{$\begin{array}{l}\text { * The kappa coefficients between the clinical classification and pulmonary } \\
\text { compared by nonparametric comparison using the bootstrap method. } \\
\text { TLC = total lung capacity } \\
\mathrm{FEF}_{25-75} \text { = forced expiratory flow between } 25 \text { and } 75 \% \text { of vital capacity } \\
\mathrm{PEF}=\text { peak expiratory flow }\end{array}$} \\
\hline
\end{tabular}

Table 5. Sensitivity, Specificity, Positive Predictive Value, and Negative Predictive Value of Total Lung Capacity, Forced Expiratory Flow Between 25 and 75\% of Vital Capacity, and Post-Bronchodilator Response Criteria in the Diagnosis of Obstructive Lung Disease in 58 Subjects With Clinical Lung Disease

\begin{tabular}{lcccc}
\hline \hline & Sensitivity & Specificity & Positive Predictive Value & Negative Predictive Value \\
\hline $\mathrm{TLC} \geq 80 \%$ predicted & 0.79 & 0.82 & 0.68 & 0.89 \\
$\mathrm{FEF}_{25-75 \%}<70 \%$ predicted & 0.79 & 0.44 & 0.41 & 0.81 \\
$\mathrm{PEF}<80 \%$ predicted & 0.68 & 0.51 & 0.41 & 0.77 \\
Post-bronchodilator response & 0.05 & 0.95 & 0.33 & 0.67
\end{tabular}

$\overline{\mathrm{TLC}}=$ total lung capacity

$\mathrm{FEF}_{25-75}=$ forced expiratory flow between 25 and $75 \%$ of vital capacity

$\mathrm{PEF}=$ peak expiratory flow

The kappa coefficient between the clinical diagnosis of obstructive lung disease and PFT interpretation using $\mathrm{FEF}_{25-75 \%}$ in the present study was poor. Although the sensitivity and negative predictive value of the $\mathrm{FEF}_{25-75 \%}$ parameter were comparable with those of TLC, the specificity and positive predictive value of $\mathrm{FEF}_{25-75 \%}$ were much lower than those of TLC. The $\mathrm{FEF}_{25-75 \%}$ is the most commonly cited indicator of small airway obstruction. The $\mathrm{FEF}_{25-75 \%}$ decreases more steeply at mild obstruction levels, which increases the sensitivity of $\mathrm{FEF}_{25-75 \%}$ with respect to detection of air flow limitations. However $\mathrm{FEF}_{25-75 \%}$ measurements can vary markedly and change in proportion to the FVC.22-24 In addition, abnormalities in mid-range flow measurements during forced exhalation are not specific for small airway disease in individual subjects. ${ }^{25}$ Interestingly, all of the subjects with asthma $(n=4$, $6.3 \%$ ) in this study, including 2 subjects with Churg-Strauss syndrome, exhibited a reduced $\mathrm{FEF}_{25-75 \%}$. Reduced $\mathrm{FEF}_{25-75 \%}$ values are known to be associated with asthma severity, and several studies have shown that reduced $\mathrm{FEF}_{25-75 \%}$ values are also associated with airway hyperresponsiveness ${ }^{21}$ and the bronchodilator response ${ }^{26}$ in subjects with asthma even with normal $\mathrm{FEV}_{1}$. In contrast, $\mathrm{FEF}_{25-75 \%}$ was shown to play only a minor role in the early detection of $\mathrm{COPD},{ }^{27}$ and there was no correlation between $\mathrm{FEF}_{25-75 \%}$ and other parameters used to measure air trapping ( $\mathrm{FVC}$ and residual volume/TLC). ${ }^{27,28}$ Thus, the relatively small number of asthma subjects included in this study may have contributed to the poor performance of the $\mathrm{FEF}_{25-75 \%}$ parameter.

The concordance and the prediction performance of PEF for the diagnosis of obstructive lung disease were comparable with those of $\mathrm{FEF}_{25-75 \%}$ in this study. The PEF criterion showed poor kappa coefficient, lower specificity, and positive predictive value but had relatively higher sensitivity and negative predictive value. In line with our results, the previous study showed that reduced PEF can be useful to detect air flow obstruction in the general population, ${ }^{6}$ and another study revealed that the presence of severe COPD can be ruled out by a normal value of PEF.7 However, the overall performance of PEF for the diagnosis of obstructive lung disease was not as good as those of TLC, and the high degree of intrinsic variability of PEF should be taken into account for interpretation. ${ }^{6,29,30}$

Our results showed that use of post-bronchodilator response was poor with respect to differentiating obstructive lung disease from subjects with restrictive spirometry patterns. One study ${ }^{31}$ explored 21 subjects with concurrent 
restrictive spirometry patterns and post-bronchodilator responses and reported that 10 of the subjects had COPD or asthma, 1 had interstitial lung disease, and 2 had chronic inflammatory disease without evidence of lung involvement. In the present study, there were only 3 subjects with post-bronchodilator responses, 1 with lung cancer obstructing the left main bronchus and 2 with interstitial lung disease. There were no COPD or asthma subjects with concurrent restrictive patterns and post-bronchodilator responses, which was suggestive of a limitation of the clinical utility of the post-bronchodilator response.

In the present study, there were 6 subjects without evidence of pulmonary disease who exhibited restrictive spirometry patterns. All 6 of these subjects had clinical disease in the abdomen, comprising the mechanical ileus $(n=2)$, acute cholecystitis $(n=2)$, small bowel intussusception $(n=1)$, and ureteral injury $(n=1)$. These subjects underwent PFT to evaluate postoperative pulmonary complication risks. Incomplete inspiration and expiration due to abdominal pain may be a possible explanation for the restrictive spirometry patterns observed for these subjects.

A fixed ratio was selected over the lower limit of normal for the interpretation of PFT results in this study. First, a reference representing the midpoint of the normal range for healthy individuals of the same age, height, sex, and ethnicity is necessary to calculate the lower limit of normal. However, the reference data for lung volumes recommended by the American Thoracic Society/European Respiratory Society Task Force are based on data from individuals in European countries, and there are no available reference data for predicting the lower limit of normal range of lung volumes in Asia. Second, the fixed ratio $\left(\mathrm{FEV}_{1} / \mathrm{FVC}<0.70\right)$ in Global Initiative for Chronic Obstructive Lung Disease guideline is more widely used than the lower limit of normal for the evaluation and management of obstructive lung disease. ${ }^{17}$

The present study had several limitations. First, the study was retrospective by design and was conducted at a single referral center. In addition, although 3,030 patients underwent all PFT with pre- and post-bronchodilator spirometry and lung volume measurements, there were relatively few subjects with restrictive spirometry patterns $(2.8 \%)$ who met our criteria for inclusion in the study. Third, FVC instead of $\mathrm{VC}$ was used due to the lack of available reference values for $\mathrm{FEV}_{1} / \mathrm{VC}$. Nevertheless, we believe that FVC is the most practical measurement (as an alternative to VC) in real clinical situations. Fourth, because it is not possible to obtain lung volume measurement in all clinics, the use of TLC may not be generalized to evaluate obstructive lung disease in all subjects with restrictive patterns of spirometry. Finally, although clinical diagnoses were made by consensus between 2 pulmonologists, there may have been information bias. To reduce this bias, we reviewed clinical information at follow-up visits; the median follow-up period after spirometry was 41.3 (interquartile range 6.2-56.6) months.

\section{Conclusions}

Obtaining an additional measurement of TLC is more useful than $\mathrm{FEF}_{25-75 \%}$, PEF, and post-bronchodilator response in diagnosing obstructive lung disease in subjects with normal $\mathrm{FEV}_{1} / \mathrm{FVC}$ and low $\mathrm{FVC}$ when clinicians suspect obstructive lung disease.

\section{ACKNOWLEDGMENTS}

We thank Jiyu Sun (Biostatistics and Clinical Epidemiology Center, Samsung Medical Center, Seoul, Korea) for support of statistical analysis.

\section{REFERENCES}

1. Pellegrino R, Viegi G, Brusasco V, Crapo RO, Burgos F, Casaburi $\mathrm{R}$, et al. Interpretative strategies for lung function tests. Eur Respir J 2005;26(5):948-968.

2. Gelb AF, Zamel N. Simplified diagnosis of small-airway obstruction. N Engl J Med 1973;288(8):395-398.

3. Lebowitz MD, Holberg CJ, Knudson RJ, Burrows B. Longitudinal study of pulmonary function development in childhood, adolescence, and early adulthood. Development of pulmonary function. Am Rev Respir Dis 1987;136(1):69-75.

4. Chiang $\mathrm{CH}$, Hsu K. Residual abnormalities of pulmonary function in asymptomatic young adult asthmatics with childhood-onset asthma. J Asthma 1997;34(1):15-21.

5. Rao DR, Gaffin JM, Baxi SN, Sheehan WJ, Hoffman EB, Phipatanakul W. The utility of forced expiratory flow between $25 \%$ and $75 \%$ of vital capacity in predicting childhood asthma morbidity and severity. J Asthma 2012;49(6):586-592.

6. Tian J, Zhou Y, Cui J, Wang D, Wang X, Hu G, et al. Peak expiratory flow as a screening tool to detect airflow obstruction in a primary health care setting. Int J Tuberc Lung Dis 2012;16(5):674680.

7. Perez-Padilla R, Vollmer WM, Vázquez-García JC, Enright PL, Menezes AM, Buist AS, et al. Can a normal peak expiratory flow exclude severe chronic obstructive pulmonary disease? Int J Tuberc Lung Dis 2009;13(3):387-393.

8. Hong Y, Ra SW, Shim TS, Lim CM, Koh Y, Lee SD, et al. Poor interpretation of pulmonary function tests in patients with concomitant decreases in FEV 1 and FVC. Respirology 2008;13(4):569-574.

9. Standardization of Spirometry, 1994 Update. American Thoracic Society. Am J Respir Crit Care Med 1995;152(3):1107-1136.

10. Choi JK, Paek D, Lee JO. Normal predictive values of spirometry in Korean population. Tuberc Respir Dis 2005;58(3):230-242.

11. Quanjer PH, Tammeling GJ, Cotes JE, Pedersen OF, Peslin R, Yernault JC. Lung volumes and forced ventilatory flows: report working party standardization of lung function tests, European Community for Steel and Coal: official statement of the European Respiratory Society. Eur Respir J Suppl 1993;16:5-40.

12. Song EH, Oh YM, Hong SB, Shim TS, Lim CM, Lee SD, et al. Selection of reference equations for lung volumes and diffusing capacity in Korea. Tuberc Respir Dis 2006;61(3):218-226.

13. Kasper DL, Fauci AS, Hauser SL, Longo DL, Jameson JL, Loscalizo J. Harrison's internal medicine. McGraw-Hill; 2015;1661.

14. Afessa B, Litzow MR, Tefferi A. Bronchiolitis obliterans and other late onset non-infectious pulmonary complications in hematopoietic 


\section{Lung Volume in a Restrictive Spirometry Pattern}

stem cell transplantation. Bone Marrow Transplant 2001;28(5):425434.

15. Chatterji RS, Panda BN, Tewari SC, Rao KS. Lung function in mitral stenosis. J Assoc Physicians India 2000;48(10):976-980.

16. Apostolo A, Giusti G, Gargiulo P, Bussotti M, Agostoni P. Lungs in heart failure. Pulm Med 2012;2012(2012):952741. doi: http://dx. doi.org/10.1155/2012/952741.

17. Global Initiative for Chronic Obstructive Lung Disease. Spirometry for health care providers, Global Initiative for Chronic Obstructive Lung Disease (GOLD). Updated 2010. http://www.goldcopd.org/ uploads/users/files/GOLD_Spirometry_2010.pdf. Accessed August 14, 2014.

18. Gardner ZS, Ruppel GL, Kaminsky DA. Grading the severity of obstruction in mixed obstructive-restrictive lung disease. Chest 2011; 140(3):598-603

19. Morris JF, Koski A, Johnson LC. Spirometric standards for healthy nonsmoking adults. Am Rev Respir Dis 1971;103(1):57-67.

20. Fleiss JL. Statistical methods for rates and proportions. New York: John Wiley \& Sons; 1981.

21. Vanbelle S, Albert A. A bootstrap method for comparing correlated kappa coefficients. J Stat Comput Simul 2008;78(11):1009-1015.

22. Sposato B, Scalese M, Migliorini MG, Di Tomassi M, Scala R. Small airway impairment and bronchial hyperresponsiveness in asthma onset. Allergy Asthma Immunol Res 2014;6(3):242-251.

23. Cockcroft DW, Berscheid BA. Volume adjustment of maximal midexpiratory flow: importance of changes in total lung capacity. Chest 1980;78(4):595-600.
24. Burgel PR. The role of small airways in obstructive airway diseases. Eur Respir Rev 2011;20(119):23-33.

25. Flenley DC. Chronic obstructive pulmonary disease. Dis Mon 1988; 34(9):537-599.

26. Simon MR, Chinchilli VM, Phillips BR, Sorkness CA, Lemanske RF Jr, Szefler SJ, et al. Forced expiratory flow between $25 \%$ and $75 \%$ of vital capacity and FEV1/forced vital capacity ratio in relation to clinical and physiological parameters in asthmatic children with normal FEV1 values. J Allergy Clin Immunol 2010;126(3):527-534.e1-8.

27. Stewart JI, Criner GJ. The small airways in chronic obstructive pulmonary disease: pathology and effects on disease progression and survival. Curr Opin Pulm Med 2013;19(2):109-115.

28. Incalzi RA, Pennazza G, Scarlata S, Santonico M, Petriaggi M, Chiurco D, et al. Reproducibility and respiratory function correlates of exhaled breath fingerprint in chronic obstructive pulmonary disease. PLoS One 2012;7(10):e45396.

29. Aggarwal AN, Gupta D, Jindal SK. The relationship between FEV1 and peak expiratory flow in patients with airways obstruction is poor. Chest 2006;130(5):1454-1461.

30. Hegewald MJ, Lefor MJ, Jensen RL, Crapo RO, Kritchevsky SB, Haggerty CL, et al. Peak expiratory flow is not a quality indicator for spirometry: peak expiratory flow variability and FEV1 are poorly correlated in an elderly population. Chest 2007;131(5):1494-1499.

31. Keddissi JI, Elya MK, Farooq SU, Youness HA, Jones KR, Awab A, Kinasewitz GT. Bronchial responsiveness in patients with restrictive spirometry. Biomed Res Int 2013;2013:498205. 